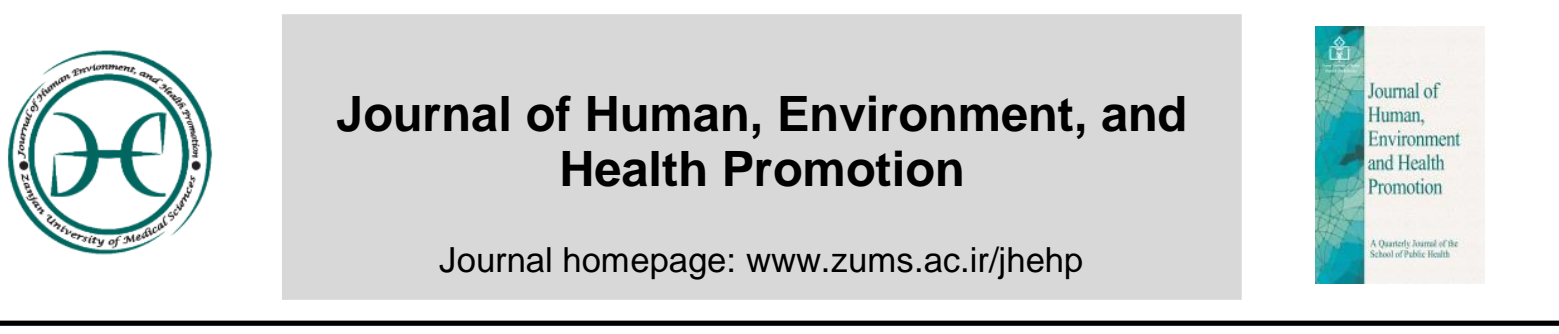

\title{
Acid violet 17 Dye Decolorization by Multi-walled Carbon Nanotubes from Aqueous Solution
}

\author{
Seyedeh Parvin Moussavi a, Mehran Mohammadian Fazli b,* \\ ${ }^{a}$ Department of School of Public Health, International Branch of Shahid Sadoughi University of \\ Medical Sciences and Health Services, Yazd, Iran. \\ ${ }^{b}$ Department of Environmental Health Engineering. School of Public Health, Zanjan University of \\ Medical Sciences, Zanjan, Iran.
}

*Corresponding author. E-mail address: mhrnmoh@zums.ac.ir

\section{A R T I C L E I N F O}

Article history:

Received September 7, 2015

Accepted November 22, 2015

Article Type:

Original Article

DOI: 10.29252/jhehp.1.2.110

\section{Keywords:}

Multi-walled Carbon Nanotubes

Adsorption

Acid violet 17

Aqueous Solution

\begin{abstract}
A B S T R A C T
Background: Dyes can cause many problems in environment. Therefore, removal of these contaminants before discharging wastewater to environment can reduce the environmental hazards. Adsorption is one of the usual processes for decolorizing from wastewater. Nanotubes are new adsorbents that can adsorb different compounds. This work aimed to investigate Acid violet 17 dye removal by adsorption using multi-walled carbon nanotubes as adsorbent from aqueous solution.

Methods: This experimental study was conducted in the batch mode and to investigate effects of parameters such as contact time, initial concentration of dye, $\mathrm{pH}$ and Multi-walled carbon Nanotubes dose on decolorization process.

Results: Results showed that the maximum dye decolorization was achieved in 3 hours. With increasing adsorbent dose, the removal efficiency was increased up to $95.9 \%$. It was found that the maximum adsorption capacity of multi-walled carbon nanotubes occurred in acidic $\mathrm{pH}$ conditions. With decreasing the initial concentration of dye, removal efficiency increase up to $83.4 \%$. Adsorption equations were described by Freundlich isotherm and Pseudo-Second order kinetic.

Conclusion: The optimal conditions for decolorization efficiency ware equilibrium time of 3 hours, $\mathrm{pH}$ of 4 , and nanotube dose of $0.4 \mathrm{~g} / \mathrm{L}$. The high $\mathrm{R}^{2}$ value of greater than 0.90 obtained showed that the experimental data agreed well with Freundlich isotherm and Pseudo-second order kinetic models.
\end{abstract}

\section{Introduction}

Dyes are one of the most dangerous chemical compounds of which are found in industrial effluents [1]. Dyes are used in textile industry, tannery, paper, plastic and the other industries widely [2-4].
They are divided to Reactive, Direct, Acidic, Disperse and Cationic on their application. Azo Reactive dyes are the largest group of industrial dyes having large variety on type and structure. 
These dyes are normally resistant to aerobic biodegradation and do not remove by usual biological treatment processes [5]. Dye decreases Sunlight penetration into water resources, so it prevents photosynthesis of aquatic plants $[1,3,6$, 7]. Allergies, Dermatitis, Skin irritation, cancers are consequences of dye in water $[1,8,9]$. So colored wastewaters should be purified before discharging to environment [7]. Several methods have developed for removal of these compounds from colored wastewaters for instance biological treatment, coagulation and flocculation, treatment by ozone, chemical oxidation, membrane filtration, Ion Exchange, photocatalytic decomposition and adsorption $[6,10,11]$.

Adsorption process moves dyes from aqueous phase to solid phase, As a result adsorbent can reproduce or stand on dry place without exposure to environment [1]. Ever usual adsorbents for example activated carbon, zeolite, clay, Industrial byproducts, agricultural runoff, biomass and polymer materials are studied in various studies. These adsorbents have low absorption capacity and their filtration is difficult [6, 10]. Discovery of Carbon Nanotubes (CNTs) by Ijima in 1991, attracted much attention of researchers [12]. Carbon Nanotubes divided to Single Walled Carbon Nanotubes and Multi Walled Carbon Nanotubes [6, 13]. CNTs are new adsorbents for removal of organic and Inorganic pollutants from water, because they have great specific surface, small size and layered structure [6]. They also have unique specific structure, mechanical and electrical properties [14, 15]. But their specific surface is less than activated carbons [9]. Structural properties for example carbon nanotubes pore diameter and porosity can determine absorption rate. They are promising absorbents due to their benefits toward other materials for instance activated carbon. Some benefits like high adsorption capacity, fast balance time and reproduce are more effective [16]. Anyway retrieval of this adsorbent normally needs to complex and time consuming filtration or centrifusion. In this regard, researchers emphasize on composition of nanotube with magnetic oxides to make a new adsorbent which provides new opportunities for achieve to favorable adsorption capacity and effective separation with high efficiency [10]. Madrakian and his associates used magnetic multi walled carbon nanotubes for removal of cationic dyes from aqueous solutions. Result of their study showed application of this method for removal of cationic dyes was effective and had high efficiency and it can be regarded as an effective method [7]. The aim of this study was the evaluation of Acid violet 17 dye adsorption rates from aqueous solutions by Multi Walled Carbon Nanotubes (MWCNTs).

\section{Material \& Methods}

Acid Violet 17 dye was produced at Dye Star Company. Its Structure is presented in figure $3[17,18]$. This study is an experimental study in batch reactor. MWCNT was from Iran Research Institute of Petroleum Industry. SEM was used for study of functional groups position on surface of nanotubes. Size and structure of MWCNTs was evaluated by TEM and nanotubes specific surface was evaluated by BET isotherm. For this purpose, presented data by Research Institute of Petroleum Industry was used. SEM and TEM of MWCNTs are showed in Fig. 1 and 2 .

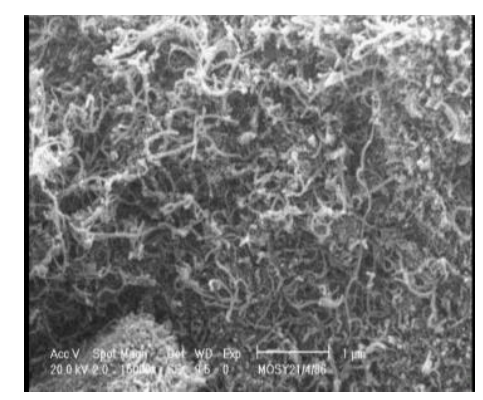

Fig. 1: SEM of Multi walled Carbon Nanotubes. 


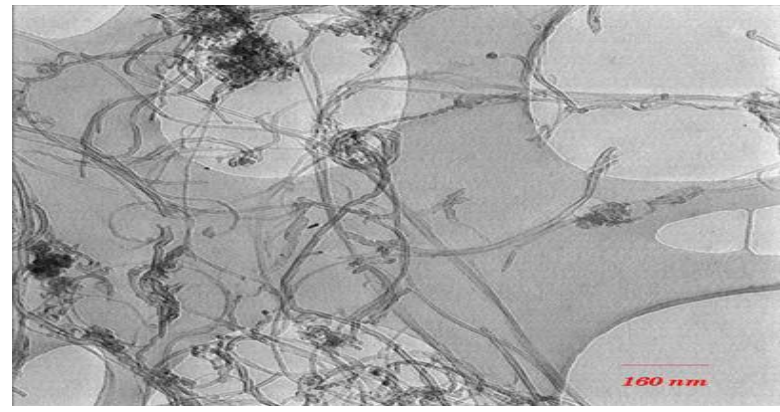

Fig. 2: TEM of Multi Walled Carbon Nanotubes.

The outer diameter of MWCNTs is 1030 nanometers, the internal diameter 3.8 nanometers, Length 10 micrometers and specific surface $270 \mathrm{~m}^{2} / \mathrm{g}$ with purity of $95 \%$. In this study, AV17 for sample preparation was used. In order to removal of nanotubes from solution, 0.2 micron Acetate Cellulose filters produced by Sartorius Corporation was used. For this study, first $100 \mathrm{mg} / \mathrm{l} \mathrm{AV} 17$ dye solution was provided then was used to provide AV17 samples with specified concentration. Different parameters including initial concentration of AV17, $\mathrm{pH}$, adsorbent dose and contact time were studied. $\mathrm{NaOH}$ and $\mathrm{HCl} 0.1 \mathrm{~N}$ for $\mathrm{pH}$ adjustment and $150 \mathrm{ml}$ Glass bottles for experiments were used. Glass bottles which contain various doses $0.4,0.6$ and $0.8 \mathrm{gr}$ adsorbent and $100 \mathrm{ml}$ AV17 dye solution with different concentrations 25 , 50,75 and $100 \mathrm{mg} / \mathrm{l}$ were set on shaker in 7 contact time periods from 15 to 180 minutes. Mixture was done in $140 \mathrm{rpm}$ intensity. At the end of each step, 0.2 micron Acetate Cellulose filters were used for separation of nanotubes from solution. AV17 dye concentration in Standard and unknown samples was measured by spectrophotometer UV/Visible model SP3000 Puls-Japan in $587 \mathrm{~nm}$ wavelength $[19,20]$. Experiments were repeated 2 times and presented results have expressed data means. AV17 dye adsorption rate calculated in formula 1 .

$q_{e}=\frac{\left(C_{0}-C_{e}\right)}{M} \times V$
$\mathrm{C}_{0}$ and $\mathrm{C}_{\mathrm{e}}$ respectively is $\mathrm{AV} 17$ dye initial and final concentration ( $\mathrm{mg} / \mathrm{l}), \mathrm{M}$ is MWCNTs dose $(\mathrm{g})$ and $\mathrm{V}$ is volume of solution (L). In order to determination of isotherm models, various adsorbent doses were added to dye solutions with $25 \mathrm{mg} / \mathrm{l}$ concentration. In this moment, $\mathrm{pH}$ of samples was 4. Solution samples were shaken in $140 \mathrm{rpm}$ for 24 hours. Then the remaining dye concentrations were measured by spectrophotometric method. Adsorption isotherms are equations to description of adsorb equilibrium state between solid and fluid phase. In this study, adsorption equilibrium experimental data were surveyed according to Freundlich and Langmuir adsorption isotherm models. Nonlinear equation of Langmuir is this like:

$q_{\mathrm{e}}=\frac{\mathrm{q}_{\mathrm{m}} \mathrm{bC}_{\mathrm{e}}}{1+\mathrm{bC}_{\mathrm{e}}}$

By integration from over equation, nonlinear equation of Langmuir changes to this:

$\frac{C_{e}}{\mathrm{q}_{\mathrm{e}}}=\frac{1}{\mathrm{q}_{\mathrm{m}} \mathrm{b}}+\frac{1}{\mathrm{q}_{\mathrm{m}}} C_{\mathrm{e}}$

In this equation, $\mathrm{q}_{\mathrm{e}}$ is adsorb amount per unit of adsorbent dose $(\mathrm{mg} / \mathrm{g}), \mathrm{C}_{\mathrm{e}}$ is adsorb equilibrium concentration in solution after adsorption $(\mathrm{mg} / \mathrm{l}), \mathrm{q}_{\mathrm{m}}$ indicates adsorption capacity and $\mathrm{b}$ is Langmuir constant which was achieved from drawing $\mathrm{C}_{\mathrm{e}} / \mathrm{q}_{\mathrm{e}}$ toward $\mathrm{C}_{\mathrm{e}}$ curves.

Nonlinear equation of Freundlich isotherm is in formula 4:

$q_{\mathrm{e}}=\mathrm{K}_{\mathrm{f}} \mathrm{C}_{\mathrm{e}}^{1 / \mathrm{n}}$

By integration from over equation, linear form of equation 4 changes to this:

$\ln q_{e}=\ln K_{f}+\frac{1}{n}\left(\ln C_{e}\right)$

In this equation, $\mathrm{C}_{\mathrm{e}}$ is adsorbed equilibrium concentration in solution after adsorption $(\mathrm{mg} / \mathrm{l}), \mathrm{q}_{\mathrm{e}}$ is adsorption capacity in equilibrium time $(\mathrm{mg} / \mathrm{g})$, and $\mathrm{K}_{\mathrm{f}}$ and $\mathrm{n}$ are Freundlich constants [21]. In order to data analysis, data mean and Correlation test were done. 
<smiles>CCN(CC)c1ccc(C(=C2C=CC(=[N+](CC)Cc3cccc([SeH])c3)C=C2)c2ccc(N(CC)CC)cc2)cc1</smiles>

Fig. 3: Structure of Acid Violet 17 dye.

Basically in adsorption process, optimal time for pollutant removal and achievement to standard amount is highly important. Optimal time is named because in which pollutant is removed favorably. If reaction time lasts more than it, process will not be economical in application and also pollutant removal efficiency will be low. In present study, dye removal efficiency in four concentrations 25, 50, 75 and $100 \mathrm{mg} / \mathrm{L}$ was studied in various contact times from 15 to 180 minutes.

\section{Results}

Results of this study showed that AV17 dye removal efficiency from aqueous solutions was depended on variable parameters like adsorbent dose, contact time, dye initial concentration and $\mathrm{pH}$. MWCNTs dose is an important variable because it determines dye removal amount. Curves of dye concentration changes toward contact time and adsorbent doses by different initial concentration of dye and different adsorbent doses was illustrated in Fig. 4 and 5. These were showed significant amount of dye was removed by $0.4 \mathrm{~g} / \mathrm{l}$ MWCNTs dose. Since $0.4 \mathrm{~g} / \mathrm{l}$ dose Compared to 0.6 and $0.8 \mathrm{~g} / 1$ is the most economical, $0.4 \mathrm{~g} / \mathrm{l}$ dose was considered as optimal dose.

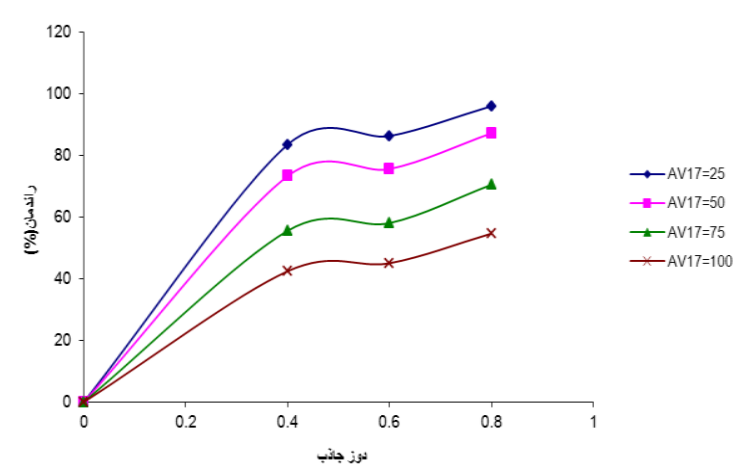

Fig. 4: Dye removal efficiency changes towards various adsorbent doses $0.4,0.6,0.8 \mathrm{~g} / \mathrm{l}(\mathrm{pH}=4$ and contact time $180 \mathrm{~min}$ ).

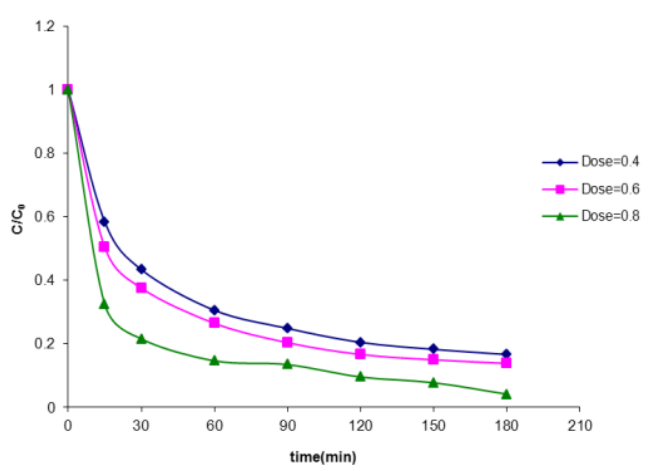

Fig. 5: Dye concentration changes towards contact times in $25 \mathrm{mg} / \mathrm{l}$ dye concentration $(\mathrm{pH}=4$ and adsorbent doses 0.4, 0.6, $0.8 \mathrm{~g} / \mathrm{l}$ MWCNTs).

Results of this item showed dye removal efficiency decreased with increasing in dye initial concentration and $\mathrm{q}_{\mathrm{e}}$ increased with increasing in dye initial concentration (Fig 6,7).

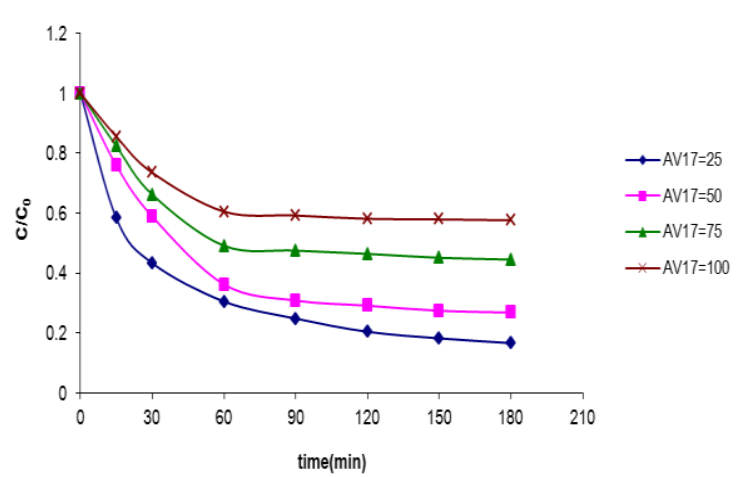

Fig. 6: Dye concentration changes towards contact times by $0.4 \mathrm{~g} / \mathrm{l}$ MWCNTs $(\mathrm{pH}=4$ and dye initial concentrations $25,50,75$, and $100 \mathrm{mg} / \mathrm{l})$. 


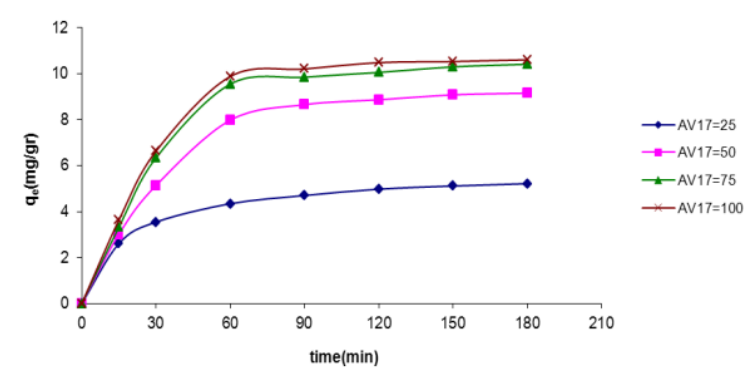

Fig. 7: Dye adsorption capacity towards contact times by $0.4 \mathrm{~g} / \mathrm{l} \mathrm{MWCNTs}(\mathrm{pH}=4$ and dye initial concentrations $25,50,75$ and $100 \mathrm{mg} / \mathrm{l})$.

Removal efficiencies for concentrations 25 and $100 \mathrm{mg} / \mathrm{l}$ were respectively achieved $83.4 \%$ and $42.4 \%$ in 180 minutes contact time. Figure 8 indicated $\mathrm{pH}$ effect on dye removal rate. This figure illustrates $\mathrm{pH} 4$ is the most effective $\mathrm{pH}$ of all ranges of $\mathrm{pH}(4,7$ and 11 ) in dye removal. Increasing $\mathrm{pH}$ from 4 to 11 causes reduction from $83.4 \%$ to $0 \%$ in removal efficiency.

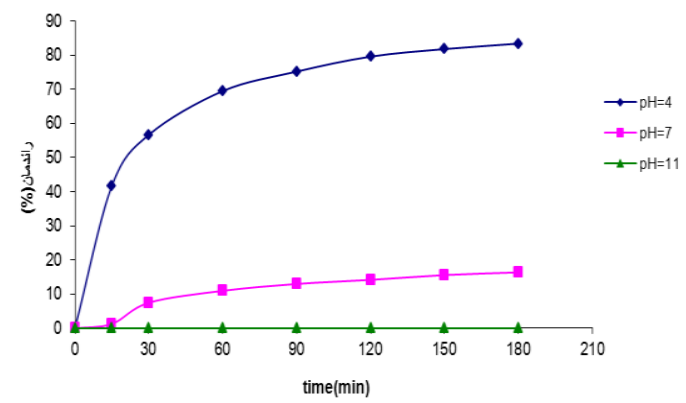

Fig. 8: Dye removal efficiency towards contact times by $0.4 \mathrm{~g} / \mathrm{l}$ MWCNTs $(\mathrm{pH}=4,7,11$ and dye initial concentrations $25 \mathrm{mg} / \mathrm{l}$ ).

Relation between adsorption rate and adsorbent dose was showed in Fig. 9.

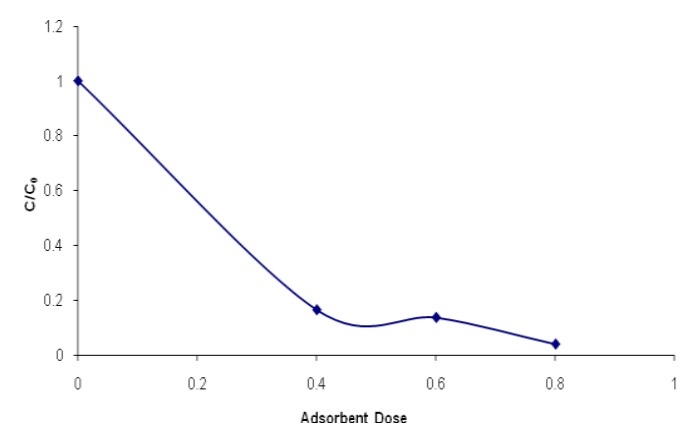

Fig. 9: Relation between adsorption rate and adsorbent dose.

In order to determination of dye removal velocity and reaction degree, pseudo-first order and pseudo- second order kinetics models were drawn. Result was showed that AV17 dye removal kinetics by adsorption process is a pseudosecond order reaction $\left(\mathrm{R}^{2}=0.982\right)$ (Fig. 10) is indicative for removal velocity constant.

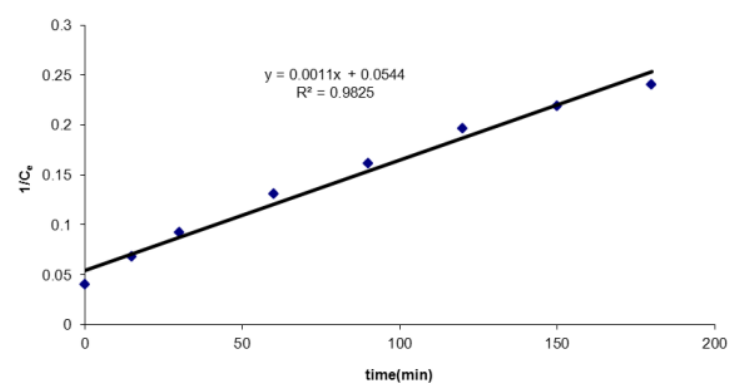

Fig. 10: Pseudo-Second order kinetic, by $0.4 \mathrm{~g} / \mathrm{l}$ MWCNTs ( $\mathrm{pH}=4$ and dye initial concentration 25 $\mathrm{mg} / \mathrm{l})$.

According to results of isotherm equations which was showed in Fig. 11, AV17 adsorption isotherm onto MWCNTs followed Freundlich isotherm $\left(\mathrm{R}^{2}=0.916\right)$.

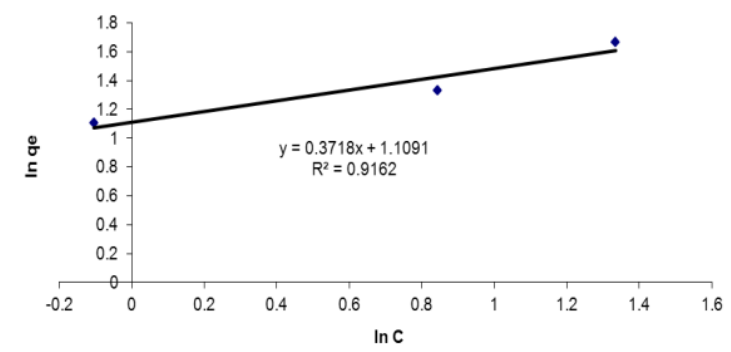

Fig. 11: Freundlich isotherm, by $0.4,0.6$ and $0.8 \mathrm{~g} / \mathrm{l}$ MWCNTs (contact time 24 hours, $\mathrm{pH}=4$ and dye initial concentration $25 \mathrm{mg} / \mathrm{l}$ ).

Consequently it can be told that optimal time for applicable cases was 60 minutes. Equilibrium time is named to which pollutant removal with time spending would be less than 5 to $10 \%$ of removal amount in initial times. In present study, equilibrium time for adsorption process was 180 minutes because after this time, adsorption rate was so little [22].

\section{Discussion and Conclusion}

Adsorption increase by adsorbent dose can be due to increasing in adsorbent area and more achievement to adsorption sites [23]. In Machado and his assistants study about $\mathrm{M}-2 \mathrm{BE}$ reactive red dye adsorption from aqueous solutions by multi walled carbon nanotubes in 2011, similar results 
were achieved. In their study due to increase in adsorbent dose, dye removal efficiency increased and $\mathrm{q}_{\mathrm{e}}$ decreased [1].

Dye removal efficiency was decreasing by increasing in dye initial concentration. $\mathrm{q}_{\mathrm{e}}$ increased when dye initial concentration had increased. Su and Lu in 2007 surveyed natural organic matter (NOM) adsorption onto carbon nanotubes. In this study adsorbed NOM onto carbon nanotubes increased with increasing in NOM initial concentration and solution ionic strength decreased with increasing in solution $\mathrm{pH}$ [24]. As results show while $\mathrm{pH}$ increased, process efficiency considerably decreased. Reason of efficiency reduction by $\mathrm{pH}$ increasing can be known ionization between adsorbent and adsorb what was caused repulsive force and adsorption efficiency reduction. Oxygen functional groups on nanotubes surfaces have important role which cause link increasing between $\mathrm{OH}^{-}$groups on nanotube surfaces in $\mathrm{pH}$ more than 4 and give it negative load. This phenomenon decreased dye removal efficiency in $\mathrm{pH}$ more than 4 . Results of present study corresponds with study of $\mathrm{Lu}$ and $\mathrm{Su}$ in 2007 evaluating NOM adsorption by carbon nanotubes [24].

Moussavi and his assistants in 2013 removed Humic Acid by Single-Walled carbon nanotubes. Their study results showed that data followed pseudo-second order reaction. Their study results correspond with present study results [25]. $\mathrm{Ai}$ and his assistants studied about removal of methylene blue from aqueous solution with magnetite loaded multi-wall carbon nanotube. Results of their study showed that adsorption process followed Freundlich isotherm $\quad\left(\mathrm{R}^{2}=0.868\right) \quad$ [10]. Results of present study corresponded to results of their study in 2011. Optimal time for applicable cases was 60 minutes. Equilibrium time for adsorption process was 180 minutes. Results of present study corresponds with achieving results of Yao and his assistants on methyl orange adsorption onto multi walled carbon nanotubes in 2011. In study of Yao and his assistants, removal optimal time was 60 minutes and adsorption equilibrium time was 180 minutes [12].

With increasing in adsorbent dose, efficiency increased and $\mathrm{q}_{\mathrm{e}}$ decreased. With increasing in initial dye concentration, dye removal efficiency decreased and $\mathrm{q}_{\mathrm{e}}$ increased. With increasing in contact time from 15 to 180 minutes, efficiency increased. Maximum adsorption occurred at first 60 minutes, so 60 minutes was considered as adsorption optimal time. Adsorption process achieved to equilibrium in 180 minutes. After this time, adsorption was so low. Results also show that with decreasing $\mathrm{pH}$ from 11 to 4 , efficiency increased. Maximum removal efficiency was occurred at acidic condition $(\mathrm{pH}=4)$, due to that $\mathrm{pH} 4$ was considered as optimal $\mathrm{pH}$. Process kinetic was described with pseudo-second order equation. Adsorption isotherm followed to Freundlich model. This study showed MWCNTs can be effective in removal of AV17 dye due to small size, large section area, crystal form,_unique network arrangement, extremely high reactivity and notable performance as adsorbent in removal of organic pollutants from aqueous solutions.

\section{References}

1. Machado FM, Ergmann CP, Fernandes TH, Lima EC, Royer B, Calvete T, et al. Adsorption of Reactive Red M-2BE dye from Water Solutions by Multi-Walled Carbon Nanotubes and Activated Carbon. J Hazard Mater. 2011; 192(3):1122-31.

2. $\mathrm{Wu} \mathrm{CH}$. Adsorption of Reactive dye onto Carbon Nanotubes: Equilibrium, Kinetics and Thermodynamics. J Hazard Mater. 2007; 144(1): 93-100.

3. Qu S, Huang F, Yu S, Chen G, Kong J. Magnetic Removal of dyes from Aqueous 
Solution Using Multi-Walled Carbon Nanotubes Filled with $\mathrm{Fe}_{2} \mathrm{O}_{3}$ Particles. $J$ Hazard Mater. 2008; 160(2): 643-7.

4. Rasoulifard MH, Taheri Qazvini N, Farhangnia E, Heidari A, Doust Mohamadi SM. Removal of Direct Yellow 9 and Reactive Orange 122 from Contaminated Water Using Chitosan as a Polymeric Bioadsorbent by Adsorption Process. $J$ Color Sci Technol. 2010; 4: 17-23.

5. Ghaneian MT, Ghanizadeh G, Gholami M, Ghaderinasab F. Application of Eggshell as a Natural Sorbent for the Removal of Reactive Red 123 Dye from Synthetic Textile Wastewater. ZJRMS. 2010; 11(4).

6. Gong JL, Wang B, Zeng GM, Yang CP, Niu CG, Niu QY, et al. Removal of Cationic dyes from Aqueous Solution Using Magnetic Multi-Wall Carbon Nanotube Nanocomposite as Adsorbent. $J$ Hazard Mater. 2009; 164(2): 1517-22.

7. Madrakian T, Afkhami A, Ahmadi M, Bagheri H. Removal of Some Cationic dyes from Aqueous Solutions Using Magnetic-Modified Multi-Walled Carbon Nanotubes. J Hazard Mater. 2011; 196: 109-14.

8. Xu S, Ng J, Zhang X, Bai H, Sun DD. Adsorption and Photocatalytic Degradation of Acid Orange 7 Over Hydrothermally Synthesized Mesoporous $\mathrm{TiO}_{2}$ Nanotube. Colloids Surf A Physicochem Eng Asp. 2011; 379(1): 169-75.

9. Kuo CY. Prevenient dye-Degradation Mechanisms Using UV/TiO $/$ Carbon Nanotubes Process. J Hazard Mater. 2009; 163(1): 239-44.

10. Ai L, Zhang C, Liao F, Wang Y, Li M, Meng L, et al. Removal of Methylene Blue from Aqueous Solution with Magnetite Loaded Multi-Wall Carbon Nanotube: Kinetic, Isotherm and Mechanism
Analysis. J Hazard Mater. 2011; 198: 28290.

11. Mishra AK, Arockiadoss T, Ramaprabhu S. Study of Removal of Azo dye by Functionalized Multi Walled Carbon Nanotubes. Chem Eng J. 2010; 162(3): 1026-34.

12. Yao Y, Bing H, Feifei X, Xiaofeng C. Equilibrium and Kinetic Studies of Methyl Orange Adsorption on Multi Walled Carbon Nanotubes. Chem Eng J. 2011; 170(1): 82-9.

13. Ravelo-Pérez LM, Hernández-Borges J, Rodríguez-Delgado MÁ. Multi-Walled Carbon Nanotubes as Efficient Solid-Phase Extraction Materials of Organophosphorus Pesticides from Apple, Grape, Orange and Pineapple Fruit Juices. J Chromatography A. 2008; 1211(1): 33-42.

14. Strong KL, Anderson DP, Lafdi K, Kuhn JN. Purification Process for SingleWall Carbon Nanotubes. Carbon. 2003; 41(8): 1477-88.

15. Chang PR, Zheng P, Liu B, Anderson $\mathrm{DP}, \mathrm{Yu} \mathrm{J}$, Ma X. Characterization of Magnetic Soluble Starch-Functionalized Carbon Nanotubes and its Application for the Adsorption of the dyes. $J$ Hazard Mater. 2011; 186(2): 2144-50.

16. Perez-Aguilar NV, Diaz-Flores PE, Rangel-Mendez JR. The Adsorption Kinetics of Cadmium by Three Different Types of Carbon Nanotubes. J Colloid Interface Sci. 2011; 364(2): 279-87.

17. Janus M, Kusiak E, Choina J, Ziebro J, Morawski AW. Enhanced Adsorption of Two Azo dyes Produced by Carbon Modification of $\mathrm{TiO}_{2}$. Desalination. 2009; 249(1): 359-63.

18. Moussavi G, Mahmoudi M. Degradation and Biodegradability Improvement of the Reactive red 198 Azo dye Using Catalytic Ozonation with $\mathrm{MgO}$ 
Nanocrystals. Chem Eng J. 2009; 152(1):

1-7.

19. Chin ML, Mohamed AR, Bhatia S. Photodegradation of Methylene Blue Dye in Aqueous Stream Using Immobilized $\mathrm{TiO}_{2}$ Film Catalyst: Synthesis, Characterization and Activity Studies. J Teknol. 2012; 40(1): 91-103.

20. Chakrabarti S, Dutta BK. Photocatalytic Degradation of Model Textile dyes in Wastewater Using $\mathrm{ZnO}$ as Semiconductor Catalyst. J Hazard Mater. 2004; 112(3): 269-78.

21. Baocheng QU, Jiti ZH, XIANG X, ZHENG $\mathrm{C}$, Hongxia $\mathrm{ZH}$, Xiaobai $\mathrm{ZH}$. Adsorption Behavior of Azo Dye CI Acid Red 14 in Aqueous Solution on Surface Soils. J Environ Sci. 2008; 20(6): 704-9.

22. Samarghandi MR, Noori Sepehr M, Zarrabi M, Norouzi M, Amraie F. Mechanism and Removal Efficiency of CI Acid Blake 1 by Pumice Stone Adsorbent. Iran J Health Environ. 2011; 3(4): 399410.

23. Crini G, Badot PM. Application of Chitosan, a Natural Aminopolysaccharide, for dye Removal from Aqueous Solutions by Adsorption Processes Using batch Studies: A Review of Recent Literature. Prog Polym Sci. 2008; 33(4): 399-447.

24. Lu C, Su F. Adsorption of Natural Organic Matter by Carbon Nanotubes. Sep Purif Technol. 2007; 58(1): 113-21.

25. Moussavi SP, Ehrampoush MH, Mahvi AH, Ahmadian M, Rahimi S. Adsorption of Humic Acid from Aqueous Solution on Single-walled Carbon Nanotubes. Asian J Chem. 2013; 25(10): 5319. 